Submitted to 1980 Int. Symp. on H.E. Physics with Polarized Beams pand Polarized

A fargets.y. Lausanne, Switzerland, Sept. 25-Oct. 1, 1980.

1 paza number 1 ;

BNL-28323

MASTER

ACCELERATION OF POLARIZED PROTON AT THE AGS*

Y.Y. Lee ${ }^{+}$

Brookhaven National Laboratory, Upton, New York 11973

ABSTRACT

The unexpected importance of high energy spin effects and the success of the ZGS in correcting many intrinsic and imperfection depolar izing resonances led us to attempt to accelerate polarized protons in the AGS. A collaborative effort is underway by the groups in Argonne, Michigan, Rice, Yale and-Brookhaven-to improve and modify the-AGS-toaccelerate polarized protons. With the appropriate funding the first polarized proton acceleration at the AGS should be possible by 1983 .

INTRODUCTION

In 1962 E.D. Courant at BNL studied ${ }^{1}$ the general problem of accelerating the polarized particles-in circular accelerators. -. Two-major-types of depolarizing resonances were identified for the particles vertically polarized
1) $\gamma G=k p \pm n \nu y$
2) $Y G=k$
Intrinsic
Imperfection

where $Y$ is the Lorentz factor, $G$ is the anomalous magnetic moment coefficient, $\mathrm{p}$ is the periodicity of the particular accelerator, $v_{y}$ is the vertical tune of the accelerator, and $k$ and $n$ are integers. Type 1) is called an intrinsic resonance, and 2 ) is called an imperfection resonance. Calculation indicated that changing the tune of the machine with the pulsed quadrupole probably works for intrinsic resonance at the ZGS and even at the AGS where the effect is ten times stronger. However, imperfection resonance might give serious difficulties. This picture became clearer when the ZGS accelerated beam to full energy and 22 imperfection resonances were successfully compensated in 1977. Accelerating to $25 \mathrm{GeV}$ with 45 imperfection resonances seems not as formidable at the AGS. During the Ann Arbor Workshop in 1977, Courant had made some computer modeling of these resonances for the AGS and the ZGS. ${ }^{2}$ The result agreed with the measurement in the ZGS very well and concluded that onemay be able to maintain the polarization up to $26 \mathrm{GeV}$. The $1978 \mathrm{BNL}$ summer study ${ }^{3}$ investigated the specific problem of accelerating polarized protons at the AGS.-.-Although there are many challenging problems,-the-.... study concluded that it is possible to accelerate polarized protons in the AGS, and provided a preliminary cost estimate.

\title{
DEPOLARIZING RESONANCES
}

Figure 1 shows the result of computer calculation of the strengths of the resonances at the AGS done by Courant and Ruth. ${ }^{2}$ The vertical bars are for the imperfection resonances and $x^{\prime} s$ are for the intrinsic resonances. The calculations are for the normal AGS acceleration rate of $\mathrm{d} / \mathrm{dt}=60 \mathrm{sec}^{-1}$ and magnet misalignment of $\pm .1 \mathrm{~mm}$ with the normalized. beam emittance of $10 \pi \times 10^{-6}$ meter-radians. The intrinsic resonances

*Work done under the auspices of the U.S. Department of Energy.

+Reporting for the BNL-ANL-Michigan-Rice-Yale collaboration.

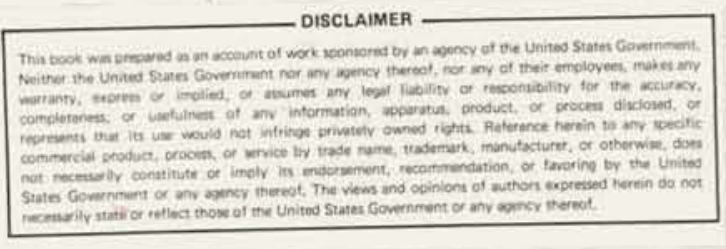




\section{DISCLAIMER}

This report was prepared as an account of work sponsored by an agency of the United States Government. Neither the United States Government nor any agency Thereof, nor any of their employees, makes any warranty, express or implied, or assumes any legal liability or responsibility for the accuracy, completeness, or usefulness of any information, apparatus, product, or process disclosed, or represents that its use would not infringe privately owned rights. Reference herein to any specific commercial product, process, or service by trade name, trademark, manufacturer, or otherwise does not necessarily constitute or imply its endorsement, recommendation, or favoring by the United States Government or any agency thereof. The views and opinions of authors expressed herein do not necessarily state or reflect those of the United States Government or any agency thereof. 


\section{DISCLAIMER}

Portions of this document may be illegible in electronic image products. Images are produced from the best available original document. 


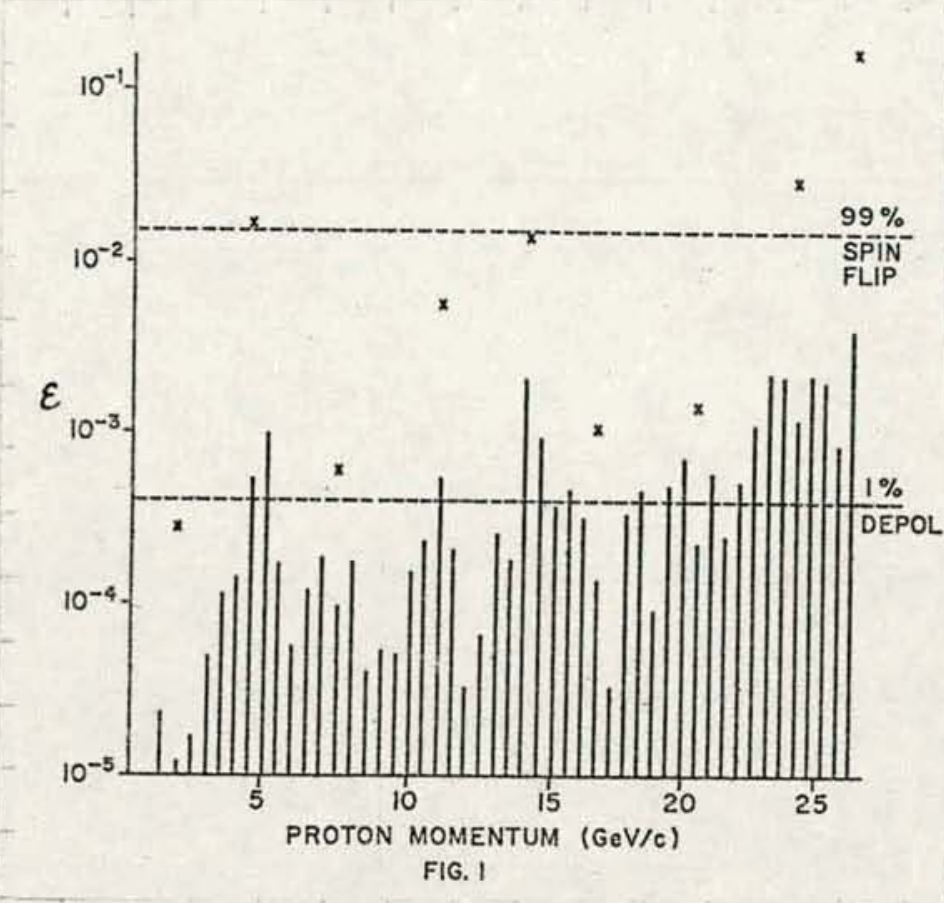

will be jumped using the st andard method used at the ZGS of pulsing of the quadrupoles to rapidly change the vertical tune of the AGS. We plan to use twelve $1 / 2$ meter long quadrupoles placed in a region of maximum betatron function $(B \cong 22 \mathrm{~m})$. Table I shows $R$. Ruth's ${ }^{4}$ calculation of estimated depolarization due to each intrinsic resonances when the quadrupoles are pulsed with a rise time of 2 microseconds. Numbers in parentheses are for fixed strength of $11.7 \mathrm{kG} / \mathrm{m}$ quadrupole strength. As can be seen in the Table, one can jump the resonances up to $\gamma \sim 25$ without difficulties, however, the resonance at $60-\nu(\gamma \sim 28.9)$ is so strong that there are no effective means of jumping the resonance. It may be possible to cross this resonance with slow spin flip. Because of the required $3 \mu \mathrm{s}$ rise time, the quadrupoles are constructed with ferrite core and ceramic vacuum chambers. Design and construction of these quadrupoles are proceeding at Michigan with collaboration from Argonne. The details of the magnet design and construction will be reported by the Michigan group. The power supplies for the quadrupoles are being deve1oped at Brookhaven. There are a few other problems one must solve. For example, in order to have stable beam in high intensity acceleration, a certain amount of momentum spread and chromaticity is required. The vertical tune spread causes the resonance jumping to be less effective. One can use sextupoles to control the spread, however, a compromise has to be found allowing both particle stability and polarization. We may have to pulse the sextupoles in order to solve this problem.

Table I

Depolarization Due to Intrinsic Resonance (2 $\mu$ s Crossing Time)

\begin{tabular}{|c|c|c|c|c|}
\hline$\underline{K p} \pm v$ & $\gamma_{\text {res }}$ & $\underline{\varepsilon}$ & $\Delta \nu \mathrm{y}$ & $\frac{\text { Polarization }\left(\mathrm{P} / \mathrm{P}_{0}\right)}{(\mathrm{P} / \mathrm{p})}$ \\
\hline $12-v$ & 1.81 & .0054 & .25 & 0.994 \\
\hline $0+\nu$ & 4.88 & .0154 & .25 & 0.958 \\
\hline $24-v$ & 8.51 & .0006 & .25 & 1. \\
\hline $12+v$ & 11.57 & .0054 & .25 & 0.994 \\
\hline $36-v$ & 15.20 & .0137 & .25 & 0.966 \\
\hline $24+v$ & 18.26 & .0010 & $.25(.21)$ & $1.000(1.000)$ \\
\hline $48-v$ & 21.89 & .0015 & $.25(.17)$ & $1.000(1.000)$ \\
\hline $36+v$ & 24.96 & .0266 & $.25(.13)$ & $0.911(0.780)$ \\
\hline $60-v$ & 28.86 & .1576 & $.25(.12)$ & $\sim 0$. \\
\hline
\end{tabular}


The strength of the Kth imperfection resonance depends on the strength of the imperfection field components of the Kth harmonics. The approach used at ZGS was to pulse a single horizontal correction field during the resonance crossing. A similar but improved technique is planned at the AGS. The horizontal field component required at $\gamma G=k$ is

$$
B_{k}(\theta)=a_{k} \sin k \theta+b_{k} \cos k \theta
$$

where $\theta$ is the azimuthal location in the ring. $a_{k}$ 's and $b_{k}$ 's will be experimentally determined by minimizing depolarization. There are 96 correction dipoles already existing in the AGS which are adequate for the practical misalignments of the main magnets. Since the resonances are spaced every $\sim 1 / 2 \mathrm{GeV}$, the control system requires some improvement. At present micro-processor based control system is planned.

ION SOURCE AND INJECTION

Since the AGS is converting to $\mathrm{H}$ - ion injection, we decided to inject polarized $\mathrm{H}^{-}$in the AGS. The polarized $\mathrm{H}^{-}$source is being developed at Argonne in collaboration with the group from Yale. The atomic stage of the source is similar to the one used at ZGS and using Cs charge exchange to form $\mathrm{H}$ ions. Present Cockroft-Walton preaccelerator will be modified extensively in order to accommodate the additional weight and volume of the ion source. The majority of the engineering work for the preaccelerator will be performed by the ANL group.

\section{POLARIMETERS}

There are three major polarimeters in this program. A $200 \mathrm{MeV}$ polarimeter is being developed and constructed by the Rice group using the high analyzing power in p-carbon scattering at $200 \mathrm{MeV}$. This is the primary monitor for the ion source polarization.

Internal polarimeter is the most important monitor for tuning the accelerator for avoiding intrinsic and imperfection resonances. The present plan is to put the polarimeter at the G10 straight section with a moving solid fiber target. The target and the polarimeter is being developed by the Michigan group. Absolute polarimeter will be placed in the primary proton line of slow external beam is also being developed by the Michigan group. Decreasing analyzing power at high energies ( $f$ ew percent at $24 \mathrm{GeV}$ ) gives the polarimeter development a formidable task.

\section{SCHEDULE}

The project started in FY 1980 with Department of Energy funding for the long lead items such as the ion source and the pulsed quadrupoles. The major amount of funding is expected in Fiscal 1981. With favorable funding the entire system is scheduled to be finished for installation in late 1982 or 1983. We anticipate an extensive testing and debugging period and first experiment shortly after.

\section{REFERENCES}

TE.D. Courant, BNL Internal Report, BNL 6433 (1962).

${ }^{2}$ E.D. Courant, Proc. Ann Arbor Workshop for High Energy Polarized Beams, pp. 94 (1977).

3 D.G. Crabb et a1., IEEE Trans. Nuc1. Sci. NS-26, 3202 (1979).

${ }^{4}$ R.D. Ruth, private communication. 